\title{
Academic Librarians' Attitudes about Advanced-Subject Degrees
}

\author{
Jennifer Mayer and Lori J. Terrill
}

Academic librarians have various opinions on the importance of advanced-subject degrees in addition to a master's in library science (MLS). The authors conducted an online survey to collect opinions from academic librarians on this topic. Arguments in favor of having advanced-subject degrees include development of research skills, credibility, and overall improved job performance. Arguments against it include the fact that the MLS is-and should continue to be-our terminal degree, inadequate salaries, and the validity of developing subject expertise via other means. The need for advanced-subject degrees may vary by many factors, including individual career goals and local institutional culture.

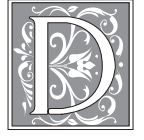

etermining the proper credentials for academic librarians is an ongoing, decades-old debate. The question of whether to pursue an advanced-subject degree in addition to the MLS, or its equivalents, is one that many academic librarians consider. The intention of this study is not to question the ALA's position that the MLS is the appropriate terminal degree for academic librarians. Rather, the primary objective of this study is to facilitate a timely discussion of the role of the advanced-subject degree in academic librarianship. The purpose is to assist both individuals and institutions in making informed decisions regarding the academic qualifications that will best meet their needs.

\section{Previous Research}

The literature related to librarians and advanced-subject degrees is limited. A literature search reveals a small body of publications on this topic that are mostly concentrated in the late 1980s and early 1990s. No major studies have been published in the library literature since 1995. A key survey on this subject appeared first as a 1989 report titled "Perceived Value of Advanced Subject Degrees by Librarians Who Hold Such Degrees," by Mary Grosch and Terry L. Weech. This report was republished as a journal article in 1991. ${ }^{1}$ Grosch and Weech's primary aim was to determine the perceived value of advanced-subject degrees to library work and career advancement. They ultimately determined that advanced-subject degrees do assist with career advancement. The respondents to their study were less assured of the correlation between their advanced-subject degree and a higher salary. 
Other publications on this subject are opinion pieces rather than research studies. These include “To 'Degree' or Not to 'Degree': Academic Librarians and Subject Expertise" by Jean-Pierre V. M. Herubel, Deanna B. Marcum's “For University Librarians of the Future, the Degree in Library Science, by Itself, Will Not Be Sufficient," and "The Education of Academic Librarians: How Many Degrees Are Enough?" by William G. Jones. ${ }^{2-4}$ These three commentaries discuss advantages and disadvantages regarding librarians and graduate-level subject degrees. Herubel agreed that getting an advanced-subject degree while working as a full-time librarian is difficult, but the benefits include enhanced job performance, campus credibility, and the installation of a scholarly ethos. Marcum noted the formidable cost of obtaining a second master's degree but stated that the advanced degree in a discipline is "critical if the librarian expects to be a partner in the scholarly process. ${ }^{5}$ Finally, Jones believed that the most important aspect is not merely holding the advanced-subject degree, but also putting it to use in order to strengthen the credibility of the academic librarian. He called for changes in library school curricula and the organization of library services to better promote interaction between librarians and other faculty and to better understand scholarly information-seeking behavior.

A small number of older studies in the past three decades also address the issue of advanced-subject degrees for academic librarians, in terms of both marketability and educational requirements. John N. Olsgaard and Jane Kinch Olsgaard reported that post-MLS requirements for directors and nondirectors rose steadily until 1976 and then declined until their study was published in $1981 .{ }^{6}$ Robert D. Swisher, Peggy C. Smith, and Calvin J. Boyer found that during the 1970s an increasing number of academic librarians possessed a second master's degree. ${ }^{7}$ They highlighted the finding that significantly more male librarians possessed or pursued a second advanced degree compared to their female counterparts.

In her 1991 thesis, Kathleen E. Aufderhaar analyzed this issue from the standpoint of job advertisements in library journals. ${ }^{8}$ Her analysis of advertisements for academic librarians revealed an increase in advertisements asking for additional advanced degrees in the 1990 issues of American Libraries, as compared to previous studies on the topic. Taking a similar approach is an online report published in 1995 by Mark Jordan focusing on advanced-subject degree requirements for Canadian librarians. ${ }^{9}$ In his small research sample, Jordan found that just over 21 percent of Canadian job announcements stipulated advanced-subject degrees as required or preferred. The inclusion of the qualification in a job advertisement was based on both institutional policy and the needs of the particular position.

The authors revisit this controversial topic nearly a decade after completion of the last comprehensive study on the subject and hope to add further insights regarding librarian attitudes, institutional expectations, and advanced-subject degrees.

\section{Methodology}

In order to address both the perceived advantages and disadvantages of advanced-subject degrees in academic librarianship, the authors of this study sought input from the academic librarians themselves. The survey was designed to measure opinions quantitatively using multiple-choice questions and to collect opinions for qualitative analysis via openended questions. It consisted of general questions answered by all respondents, gathering basic information about the 
librarians and their institutions; the participants' opinions regarding advancedsubject degrees; and whether the respondents have advanced-subject degrees or are working on them. Respondents then were directed to one of two sets of questions depending on whether they have (or are working on) an advanced-subject degree. Finally, the opportunity to submit additional comments was an option for all respondents. The text of the survey can be found in the appendix to this article.

The intention of the study was to obtain responses from a diverse group of academic librarians in terms of both geography (primarily within the United States) and librarianship specialty. To this end, the authors created a Web-based survey. Messages were posted to a variety of professional library electronic mailing lists to disseminate the survey, including four regional library lists (U.S.) and fourteen lists focused on either specific library function (e.g., collection development) or specific library subject area (e.g., science librarianship). In a few cases, it was impossible to verify whether the message was actually posted to the list because the authors do not subscribe to all of them. Although this method did not necessarily result in a completely representative sample of academic librarians in the U.S., the authors decided it was the best way to attract librarians holding diverse and well-formed opinions on this subject. The survey was available in November 2003. The resulting sample used in the analysis consists of 1,213 individual responses.

\section{Profile of Respondents}

Basic information was collected from survey respondents related to their jobs and institutions. The respondents indicated their primary job responsibilities, but because they could check more than one box, the total percentage exceeds 100 percent. The majority have some reference and/or instruction duties, constituting 63.15 percent of responses, followed by collection development at 46.41 percent, administration at 30.75 percent, and cataloging at 22.67 percent. All other areas of librarianship were selected by less than 20 percent. Respondents were 78.32 percent female and 21.19 percent male; 0.49 percent did not indicate gender. Six hundred thirty-eight respondents (52.60\%) either have an advanced-subject degree or are in the process of working on one, and 575 respondents $(47.40 \%)$ do not have an advanced-subject degree.

Respondents were asked to indicate which of four categories best describes their institution, with categories based on the highest degree granted by the institution (a simplification of the Carnegie Classification system). Most respondents $(57.30 \%)$ work in doctoral-granting institutions, roughly a quarter of respondents work in institutions where the master's degree is the highest degree granted, and those affiliated with community/junior colleges and institutions where the baccalaureate is the highest degree granted each comprise less than 10 percent of respondents. Respondents were asked to describe their status within their institutions with the following results: 59.44 percent faculty, 26.96 percent academic professionals, 11.05 percent staff, 1.98 percent contract/temporary employees, and 0.58 percent no answer. Two questions were asked to obtain additional information about those librarians with faculty status. However, because faculty status takes on many forms with a variety of expectations and because a significant portion of respondents do not have faculty status, roughly 40 percent of respondents indicated "not applicable" or did not answer these questions because the questions did not pertain to their situation. Just less than 15 percent of all respondents indicated that an advanced- 
subject degree is required for promotion within their institution, and 28 percent indicated that working on an advanced degree counts toward their research/ scholarship requirements.

The authors inquired about the requirements and expectations of respondents' current positions. When asked about advanced-subject degree requirements (master's or doctorate), 52.27 percent of respondents indicated that an advancedsubject degree is not a requirement for their job, 25.64 percent indicated that one is preferred for their position, 20.61 percent indicated that one is required for their position, and 1.48 percent did not answer the question. When asked about the degree of subject specialization their position requires, 18.05 percent of respondents have a high degree of subject specialization; 43.36 percent have some subject specialization required, but also general knowledge; 22.75 percent have limited subject specialization and mainly general knowledge; 15.50 percent have no subject specialization required; and 0.33 percent did not respond.

Those respondents with advancedsubject degrees and those working on them were asked for information on the subject areas of all their advanced-subject degrees. The general areas of study with the greatest number of responses are the humanities at 40.44 percent, social sciences at 18.81 percent, education at 11.29 percent, and fine arts at 10.03 percent. All other subject areas were selected by less than 10 percent of respondents. Respondents also were asked about the order in which the graduate degrees were obtained. Most respondents obtained their subject degree first (55.49\%), followed by those who obtained their library degree first $(38.09 \%)$ and finally those who worked on their degrees simultaneously $(4.70 \%)$. The question was not answered by 1.72 percent of respondents.

\section{Results}

At the core of the research project are the opinions of academic librarians on advanced-subject degrees in addition to the MLS (or its equivalents). To this end, all the respondents were asked: "In your opinion, should academic librarians also have advanced-subject degrees (master's or doctorate)?" The majority of respondents (686, or $56.55 \%$ ) answered, "yes, for certain positions." The other choices came out fairly even with 161 (13.27\%) answering "yes, definitely," 164 (13.52\%) answering "neutral/no opinion," and 196 (16.16\%) answering "no, advancedsubject degrees are not necessary." Six respondents $(0.49 \%)$ did not answer the question. The results of a multivariate analysis show that most categories of respondents (i.e., by job responsibility, sex, type of institution, position status, qualifications of position, level of subject specialization) had a similar distribution of responses among the four answers as compared to the percentages for all respondents. Only a few categories showed responses where the deviations from average are worth noting. Librarians for whom an advanced-subject degree is necessary for promotion and those for whom it is a job requirement reported in higher-than-average percentages that academic librarians should definitely have advanced-subject degrees $(30.86 \%$ and $28.00 \%$, respectively). A comparatively higher percentage of those holding positions where advanced-subject degrees are preferred felt that academic librarians in certain positions should have advancedsubject degrees (66.56\%). A higher-thanaverage percentage of librarians (25.53\%) with no subject specialization in their jobs said that advanced-subject degrees are not necessary for academic librarians.

The authors compared the group of respondents who have or are currently working on advanced-subject degrees 
to those who do not have them. The majorities in both groups think that librarians in certain positions should have advanced-subject area degrees, with 60.03 percent of the people with or working on degrees and 52.70 percent without degrees of that opinion. There was more variation in opinion in the other categories (figure 1). Although those without advanced-subject degrees are much more likely to feel they are unnecessary for academic librarians, still most respondents feel they are appropriate for some positions. Those

FIGURE 1

Should Academic Librarians have Advanced Subject Degrees?

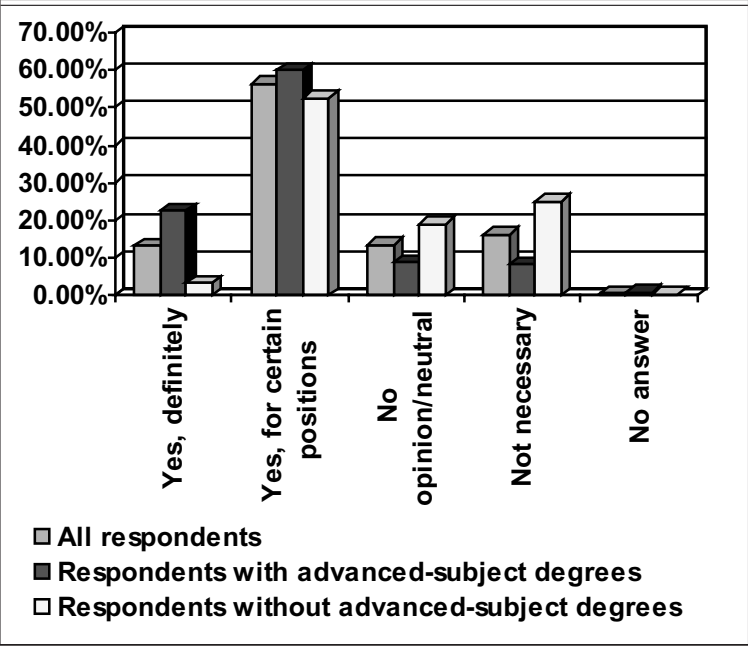
respondents with or working on advanced-subject degrees overwhelmingly feel that advanced-subject degrees are necessary for at least some, if not all, positions. Despite the variations noted among certain categories of academic librarians, the study's sample demonstrates that most librarians recognize that there is a place for advanced-subject degrees in the field of academic librarianship.

Respondents who do not have an advanced-subject degree were asked if they would like to get one and the reasons behind their decision. Forty respondents (6.96\%) gave reasons for both getting a degree and not getting one, 251 (43.65\%) only cited reasons for getting one, and $284(49.39 \%)$ only cited reasons for not getting one. Among the reasons given for wanting to get an advanced-subject degree, the most popular choice was personal fulfillment $(85.91 \%)$, followed by greater marketability when searching for a job $(62.89 \%)$, help in career advancement $(50.86 \%)$, help in job performance (37.46\%), higher salary (34.02\%), and job requirement (3.09\%). An option provided for write-in responses was chosen by 7.56

percent of respondents, who cited free tuition, status among peers and other faculty, help with promotion, and preparation for a career change as reasons for obtaining an advanced-subject degree.

Among those respondents citing reasons not to get an advanced-subject degree, 56.79 percent chose "I do not have the time," 48.46 percent chose "I do not think I need one," 36.42 percent chose "I do not have the money," 24.07 percent chose "My library does not support it," 23.77 percent chose "I do not want one," and 8.95 percent chose "Appropriate graduate-degree program is not accessible to me (i.e., none offered in my geographic area or through a distance education program)." Among those selecting "other" (29.32\%), common reasons included respondents nearing retirement/end of library career, salaries are not adequate to compensate for additional expense of degree, experience is more important, and not being motivated enough to go back to school.

The survey respondents who have an advanced-subject degree indicate, overall, that having a subject degree is important 
to an academic librarian in multifaceted ways. The top reasons cited for deciding to pursue a graduate degree are as follows: "personal fulfillment" (37.46\%), "intention of working in the subject field" (37.30\%), "help in career advancement as a librarian" (26.18\%), "greater marketability when searching for a library job" (23.04\%), and "to help in job performance as a librarian" (18.03\%). Also of note is that many respondents ( $41.22 \%$ ) obtained their advanced-subject degree before deciding to become a librarian.

Those respondents holding or working on advanced-subject degrees were asked to rate their feelings about the following four statements related to advanced subject degrees:

- "Having an advanced-subject degree is important to my career advancement."

- "Having an advanced-subject degree is beneficial to my job performance."

- "I would advise a person interested in becoming an academic librarian to pursue an advanced-subject degree."

- "If I were doing it over, I would get an advanced subject degree again."

The respondents also were able to make open-ended comments on each statement. Unfortunately, a significant portion of respondents answered the open-ended questions without marking the corresponding multiple-choice rating or skipped some questions entirely, leaving the statistical validity of the multiplechoice ratings in question. Therefore, in analyzing the results of this section, the authors rely on qualitative analysis alone. However, in the case of all four questions, the majority of respondents who did fill out the multiple-choice ratings either strongly agreed or agreed with the statements. Each of the topics is discussed below.

There are many reasons why librarians say an advanced-subject degree is important to career advancement. Often the second degree is required for librarian and library administrator positions, assists with gaining tenure and promotion, and gives librarians better credibility on campus and with other academic librarians. It also can be vital to the development of research skills not taught in library school, can provide increased opportunities for scholarly projects, immerses one in academic culture, and exemplifies a commitment to the importance of lifelong learning. Finally, it helps with job performance, may lead to higher salaries, opens doors for teaching opportunities, and makes an individual more marketable. One librarian commented, "I have been passed over for jobs because I lack a second master's (this includes a part-time temporary position)."

There also were a few comments arguing against the necessity of an advancedsubject degree for career advancement. Many people view degrees beyond the MLS as supplemental-helpful, but not necessary. One respondent wrote, “While it is well regarded, it does not determine my success as a librarian." Others cited that it helped most by opening doors early in their careers, but later it was their experience that counted most.

Many of the academic librarians completing the survey agreed that an advanced-subject degree is important to their job performance. The main themes supporting this position are similar to the ones appearing in regard to career advancement and include the development of research skills and intellectual growth. Also, an advanced-subject degree helps with a variety of librarian jobs, including reference, bibliographic instruction, cataloging, collection development, distance education, and electronic resources. One librarian said, "Because I do selection and oversee other selectors, subject expertise is extremely important. Whether 
one is writing collection policies, making storage decisions, creating subject Web pages, or doing instruction for graduate students, there is no substitute for subject expertise." Finally, the fact that the degree helps build credibility with the university community also was mentioned.

In terms of job performance, others feel the helpfulness of the degree may depend somewhat on the position one holds. Respondents noted that it could be helpful for collection development or specialized reference, but less helpful for generalist positions. Some simply said that the degree is irrelevant to their performance, with experience as a librarian being more important. Respondents cited few drawbacks. Some of those librarians working on advancedsubject degrees while working as a librarian noted how their energies were divided between work and school and that work on the degree took time away from their job responsibilities. Some felt that subject degrees are "too limiting" and that "librarians should be generalists."

Do survey participants advise other academic librarians to obtain an advanced subject degree? Yes, for some of the reasons listed above, mainly, higher salary, marketability, credibility, research skills, and confidence. One librarian said, "An advanced degree is vital to creating the scholar-librarian." Few respondents indicated that they would not recommend getting an advanced-subject degree. Arguments against include the time and attention working on the degree may take away from library work and the fact that one can still be a good librarian without one. However, there also were many mixed responses. "It depends" was not an uncommon response. Mitigating factors include the person's career track, personal motivation, and institution, for example. One person pointed out, "Could be a waste of time and money or a terrific boost." A few respondents also reemphasized that the MLS is still the basic qualification for librarianship. Others felt that, although not necessary, advanced-subject degrees are becoming the norm in academic librarianship and noted that they are a requirement for some positions. As one person answered, "Philosophically, I do not believe in it, but because it is a requirement for so many academic library jobs, it is probably advisable to have an advanced [subject] degree."

Would the respondents pursue and obtain the advanced degree again? The overwhelming response was positive. Several commented that it is an important supplement to the MLS. Other general comments include that a broader perspective outside the library is beneficial and also makes for a more valuable librarian. Personal fulfillment and lifelong learning also were mentioned. Several respondents indicated they wanted to get a Ph.D. in order to advance to upper-level library administrative positions. Still other reasons why librarians would pursue an advanced-subject degree again include: keeping career options open; improving research skills vital to librarianship; helping with teaching skills; and that it is a job requirement. Many said they wished they had gotten the degree earlier. Very few respondents indicated they would not get one if doing it again. One respondent pointed out, "Experiences other than degree-based learning have been more valuable to me.... I believe I benefited more professionally from the additional [library science] courses and interaction with faculty and peers in those courses than in the master-level subject courses."

\section{Discussion}

The authors provided all respondents with the opportunity to submit open-ended comments on the topic of advanced-sub- 
ject degrees. In analyzing the responses in combination with the other open-ended questions discussed in the previous section, a number of major themes emerged that both supported and opposed the opinion that academic librarians should have advanced-subject degrees.

When arguing against the need for advanced-subject degrees, one of the primary issues raised by respondents is the fact that the MLS is the terminal degree for our profession. There were many expressions of this opinion, including: "The base of our job is to help identify, [collect], organize, and lead others to information. It is more important to know theories and functions related to information science than a subject." And, "If we are treated with a lack of respect and seriousness if we 'only have an MLS,' what is the point of having professional graduate training for librarians at all?!?!?!” The MLS should be the one absolute credential for academic librarianship and to suggest otherwise might weaken the credibility of our degree and our profession. By suggesting that the MLS is not enough, the degree is, in effect, devalued. Other arguments against the need for advancedsubject degrees also adhere to this primary philosophical argument, but have practical aspects, too.

Another common opinion among respondents is that an advanced-subject degree is not necessary in order to be a good librarian and that learning and updating library and information skills are what count the most. One respondent wrote, "It is more important and valid to require ongoing training in assessment skills, information literacy standards, technology skills, marketing, and more. These are the skills that I need in order to do my job on a daily basis." Speaking specifically about job performance, one manager noted, "I currently manage more than thirty in their collection management responsibilities....
The ones with advanced degrees have not been noticeably more effective in their jobs than those who lack them."

Several respondents asserted that an advanced-subject degree is not the only way to gain subject expertise. One commented, "I think that a motivated person can get a subject specialty without getting an advanced degree beyond the MLS. They can take classes, read and study extensively, stay close to faculty and others in the specialty, and come to a sufficiently high level of expertise." Another concurred that it is the subject knowledge and not the degree per se that helps: "Actually, it's not that it's an advanced degree, but that it's added knowledge in any field.... Any added knowledge, regardless of level or field, will naturally enhance my ability to help my library's users." Another point made by several respondents is that individual classes can help, but often there is no recognition for such efforts. A generalist probably would benefit more from taking a broad range of courses (undergraduate or graduate level), but, unfortunately, the reality in many institutions is that taking a range of courses that does not add up to a credential does not garner the respect that getting a degree does.

The need for flexibility as a librarian is another reason respondents argued against the advanced-subject degree. Some feel that a subject specialty detracts attention from one's ability to be a generalist. One person argued, "Subject degrees tend to focus you more on that subject and less on everything else." Also, respondents brought up the fact that librarians may be expected to adapt to working within any subject specialty. One respondent noted that at some institutions subject responsibilities are subject to change. Just because a librarian has a particular subject credential does not mean he or she will end up working in 
that subject area; one may end up working in a different subject specialization by either choice or circumstance. All the effort put into a subject degree may or may not eventually be put to use, and for some people that uncertainty is reason enough not to pursue an advanced-subject degree. Moreover, as a practical concern, a librarian may end up working in a particular subject specialty but may not have the appropriate undergraduate background to pursue an advanced degree in that field. In a case such as that, it is far more practical and time effective to seek out subject knowledge via avenues other than an advanced degree.

The fact that current salaries for librarians do not justify the costs of obtaining additional advanced degrees is another point made by respondents. Many librarians feel that our profession is undercompensated and to require further credentials for academic librarianship without a commensurate increase in compensation is unreasonable. Another practical concern relating to the problem of low salaries is that requiring an advanced-subject degree will further increase the difficulty of recruiting new people into the profession. In addition, this requirement could limit the pool of potential job applicants an institution has to choose from. For a profession already struggling with low salaries, raising expectations for academic credentials just does not make sense. As one person put it, "It is pretty sad that librarians are required in some places to have a second master's or more-unless they are specialists in some way. The profession has a hard enough time recruiting without adding requirements without appropriately compensating."

There are, of course, costs associated with getting an advanced-subject degree in addition to the financial consideration of salaries. Tuition and associated fees may or may not be reimbursed by a librarian's institution. Books and other required instructional materials are an expense that individuals often have to pick up themselves. Seeking the degree as a full-time student could delay the librarian's entry into the profession, which would have practical implications for his or her financial situation. The other significant cost is time. Even part-time graduate work can be very time-consuming, perhaps taking time away from one's job duties as a librarian and impacting one's personal life. Those librarians with research requirements, especially, may find the competing interests to be too much in terms of time and intellectual commitment. For those entering the library profession later in life, the time left in their working career may not make the time taken to get an advanced-subject degree a prudent investment.

For many respondents, the answer to whether a librarian should have an advanced-subject degree is "It depends." Many variables can factor into the decision to get an advanced-subject degree, including type of library, personal career goals, whether to be a generalist or a specialist, area of librarianship (e.g., reference, collection development, cataloging, etc.), and personal commitment. One librarian commented, "I think that only reference or instruction librarians in large doctoral-granting institutions should be required to have second master's degrees." Several noted that it is really not necessary in community colleges.

It is quite clear from the comments received that institutional culture plays a large role in the perception of advancedsubject degrees. Some institutions require advanced degrees for hire or promotion. However, librarians with advanced-subject degrees noted that they sometimes are looked upon with suspicion as being "overeducated" or "overqualified," and in some cases, are even seen as threaten- 
ing by librarians without them. Some institutions even discourage work on advanced-subject degrees.

Among the reasons why librarians are in favor of advanced-subject degrees are those related to career advancement. The advanced degree ties to tenure and promotion situations in a variety of ways. Many institutions require an advancedsubject degree for promotion beyond assistant librarian/professor; others require a Ph.D. to obtain the status of full librarian/professor. A more indirect way the advanced-subject degree relates to issues of tenure and promotion is that pursuing the advanced degree may generate ample material for scholarly publications and presentations in a field of interest.

Marketability is another justification for academic librarians to get an advanced-subject degree. As one respondent said, "An MS degree in science has opened almost every door I knocked on in looking for positions across the last fifteen years." Others point out that the additional degree is a "preferred qualification," "shows a level of commitment" to potential employers, is "an advantage," and "distinguished me from other job applicants."

Monetary incentives are another reason some respondents support the advanced-subject degree for librarians. Some institutions offer full-tuition reimbursement as well as time off to obtain the degree. Others offer raises for the librarians who have an advanced degree. One respondent said that obtaining an advanced-subject degree results in an automatic salary increase.

Many respondents argued that an advanced-subject degree is important for developing research skills not learned in library school. One librarian said, "Library science degree programs are weak in research methods. My subject degree required extensive training in research design and quantitative methods." In addition, numerous library schools do not require a thesis, which contributes to the development of research and writing skills at a scholarly level. One librarian noted, "One of the most positive effects that I have found from my advanced-subject degree is that I was better prepared than most librarians I know for research and publication (especially in terms of having something to research!)."

The correlation between an advancedsubject degree and increased levels of credibility and confidence was another prominent theme. An enhanced reputation with faculty and graduate students is an important result of having an advanced-subject degree, according to many of the librarians who took the survey. Some librarians feel that having the degree opened more doors for them in terms of networking with faculty, other librarians, and other scholars in the subject field both on and off their affiliated campus. Realistically speaking, the advanced-subject degree does make inroads with certain kinds of teaching faculty. Furthermore, opportunities to teach on campus may not be available without the advanced-subject degree. One respondent said, "While the MLS is a terminal professional degree, it's not the one that's recognized and taken seriously as a faculty credential in the academic world. We are recognized as faculty to the extent that we hold recognizable terminal degrees. Academic librarians should hold research degrees in their subjects of expertise. We're better research librarians for it."

The commitment to understanding academia, lifelong learning, and personal fulfillment are further benefits of getting advanced-subject degrees in the eyes of some academic librarians. Respondents noted that obtaining an advanced-subject degree helps to "understand higher edu- 
cation and how it works" and "provides insight into the academic process." Many respondents also value lifelong learning. One survey participant said, "The day you no longer have the desire to continue learning is the day you should stop being an academic librarian." Related to lifelong learning is personal fulfillment. One librarian said, "I think that people should get subject degrees if they are passionate about the topic, not for career advancement."

\section{Summary and Conclusions}

In these investigations, the authors confirmed that academic librarians have strong opinions on the topic of advanced-subject degrees. Academic librarians with and without advancedsubject degrees argued both for and against them. Survey respondents value core library skills but also recognize the value of intellectual curiosity and enthusiasm for academic pursuit. Pursuing an advanced-subject degree is strong evidence of both these traits, although not the only way those qualities may be expressed. Most respondents recognize a place for advanced-subject degrees within academic librarianship, although some feel it is not the only way to gain subject expertise. Survey respondents also are concerned with how to best fit into the academic culture of their respective institutions - how to establish credibility and relationships with faculty, staff, and students to become an integral part of learning, teaching, and research activities. An important point to remember from one of the respondents is: "How useful the additional education is will ultimately depend on the attitudes with which an individual embraces and utilizes the additional education."

The authors of this study have personally found the pursuit of advanced-subject degrees to be quite different from their li- brary school experiences and, ultimately, of great value to the practice of librarianship. They both found pursuing degrees while working full-time as librarians to be challenging, but rewarding, work. Ultimately, as library school students and librarians grapple with this issue, they need to keep in mind their own career goals, their institutional situation, their need for future flexibility, and their personal level of commitment before making the decision. As libraries set policies on job and promotion requirements, they will need to look to their own unique needs and the culture of the larger academic institutions of which they are a part. The question of academic librarians and advanced-subject degrees does not have an easy answer, but it is hoped that this article has provided some valuable insights into the debate to help both individuals and institutions make informed decisions.

\section{Further Research}

Some of the survey answers touched on additional themes that were not the focus of this research, but that are important future considerations. A large number of respondents indicated that the MLS does not meet the educational needs of academic librarians, especially in terms of teaching research skills. This raises a serious question: Is the MLS curriculum rigorous enough? One survey respondent stated: "I often wonder if a second master's is seen as desirable because the MLIS is really a professional degree, usually course-based, and not sufficiently 'academic."'

A few respondents brought up the issue of the Ph.D. in library science. Some librarians see the Ph.D. in library science as a better "next step" than a subject degree. If we value our field of study, why not pursue its highest credential rather than another master's-level degree in a subject field? 
The subject Ph.D. versus the subject master's degree for academic librarians is another issue of concern: Is the Ph.D. becoming the standard in some institutions? Some comments strongly indicate that the controversy continues over recruiting individuals with Ph.D.s (but no MLS degree) to librarianship, especially in upper-level administrative positions. The discussion will continue regarding what role, if any, holders of advanced-subject degrees (but no MLS) should play in alle- viating the anticipated librarian shortages due to retirements.

Many respondents continue to raise the question of academic librarians as faculty members. There are practical and philosophical issues surrounding academic librarianship relating to education, credentials, and status. Judging from the survey comments, all of these issues strike a nerve with academic librarians and will continue to generate debate.

\section{Notes}

1. Mary Grosch and Terry L. Weech, "Perceived Value of Advanced Subject Degrees by Librarians Who Hold Such Degrees," Library \& Information Science Research 13 (1991): 173-99.

2. Jean-Pierre V. M. Herubel, “To 'Degree' or Not to 'Degree': Academic Librarians and Subject Expertise," College \& Research Libraries News 52 (1991): 437.

3. Deanna B. Marcum, "For University Librarians of the Future, the Degree in Library Science, by Itself, Will Not Be Sufficient," Chronicle of Higher Education 36, no. 46 (1990): B1, B3.

4. William G. Jones, "The Education of Academic Librarians: How Many Degrees Are Enough?" College E Research Libraries News 52 (1991): 584-86.

5. Marcum, "For University Librarians of the Future," B3.

6. John N. Olsgaard and Jane Kinch Olsgaard, "Post-MLS Educational Requirements for Academic Librarians," College and Research Libraries 42 (1981): 224-28.

7. Robert D. Swisher, Peggy C. Smith, and Calvin J. Boyer, "Educational Change among ACRL Academic Librarians," Library \& Information Science Research 5 (1983): 195-205.

8. Kathleen E. Aufderhaar, "Educational Requirements beyond the MLS for Academic Librarians in 1990" (master's thesis, Kent State University, 1991).

9. Mark Jordan, "Advanced Degrees in Addition to the MLS: A Survey of Recent Hiring Practices in Canadian Academic Libraries," (n.p.: Target Library \& Information Services, 1995). Available online from http://www.targetinform.com/resources/degrees/. 


\section{APPENDIX \\ Survey on Academic Librarians and Advanced Subject Degrees}

1. My primary job duties include the following (check all that apply): 1

$\square$ Administration $\square$ Reference/Instruction $\square$ Cataloging 1

acquisitions $\square$ Collection Development $\square$ Outreach 1

口 Systems $\square$ Other, please describe: 1

2. Which best describes your institution?

- Community college/junior college (mainly offers associate's degree and certificate programs)

- Baccalaureate is highest degree granted.

- Master's is highest degree granted.

口 Doctorate is highest degree granted.

3. Sex $\square$ Female $\square$ Male

4. Which best describes your current position status? 1

- Faculty $\square$ Academic professional 1

ㄴ Staff $\square$ Contract/Temporary employee 1

5. If you have faculty status, is an advanced-subject degree (master's or doctorate) required for promotion in your institution (in addition to a master's degree in library science)? $\square$ Yes $\square$ No $\square$ Not applicable-I do not have faculty status. 1

6. If you have faculty status with research/scholarship requirements, does working toward and completing an advanced-subject degree count toward your research/scholarship requirements?

\Yes $\square$ No $\square$ Not applicable-I do not have faculty status. 1

7. Degree requirements of your current position:

- Advanced-subject degree (master's or doctorate) is required.

- Advanced-subject degree (master's or doctorate) is preferred.

- Advanced-subject degree (master's or doctorate) is not a qualification for my job.

8. Which best describes your current position?

- High degree of subject specialization required

- Some subject specialization required, but also general knowledge

- Limited subject specialization, mainly general knowledge

- No subject specialization required

9. In your opinion, should academic librarians also have advanced-subject degrees (master's or doctorate)?

- Yes, definitely.

- Yes, for certain positions.

- Neutral/No opinion

№, advanced subject degrees are not necessary. 
10. Do you have an advanced-subject degree in addition to your library degree?

Yes $\square$ No $\square$ I am currently working on an advanced-subject degree. 1

10a. If yes, how many master's degrees?

$10 \mathrm{~b}$. If yes, how many doctoral degrees? 1

\section{CONTINUE}

[Note: Respondents answering "Yes" or "I am currently working on an advanced subject degree" on question 10 are directed to the "Yes Section" (questions 11-17a) and those answering "No" are directed to the "No Section" (questions 18-18b).]

\section{Yes Section}

11. Which general subject area best describes your advanced-subject degree(s) (master's or doctorate) (check all that apply):

\begin{tabular}{|c|c|c|}
\hline Humanities & F Fine Arts & Social Sciences \\
\hline Natural/Physical Sciences & a Health Sciences & Mathematics/Statistics \\
\hline Engineering & a Computer Science & Business \\
\hline Agriculture & 口 Public Administration & \\
\hline Juris Doctor & Education & \\
\hline Other, please describe: & & \\
\hline
\end{tabular}

12. In what order did you work on your graduate degrees?

- Subject degree first, then library degree

- Subject degree and library degree worked on simultaneously

ㄴibrary degree first, then subject degree

13. What factors played a role in your decision to pursue an advanced-subject degree? (Check all that apply.)

ㄱob requirement for library position

- Help in job performance as a librarian

- Help in career advancement as a librarian

- Higher salary as a librarian

- Greater marketability when searching for a library job

口 Personal fulfillment

- Obtained the subject degree with the intention of working in the subject field

- Obtained the subject degree before deciding to become a librarian

口 Other, please describe:

Please rate how you feel about the following statements:

14. Having an advanced-subject degree is important to my career advancement.
a Strongly agree
a Agree
- Neutral
口 Disagree
ㄴ Strongly disagree

14a. Please explain:

15. Having an advanced-subject degree is beneficial to my job performance.
․ Strongly agree
- Agree
口 Neutral
․ Disagree
Strongly disagree

15a. Please explain: 
16. I would advise a person interested in becoming an academic librarian to pursue an advanced-subject degree.
a Strongly agree
a Agree
- Neutral
口 Disagree
a Strongly disagree
16a. Please explain:

17. If I were doing it over, I would get an advanced-subject degree again.
- Strongly agree
Agree
- Neutral
D Disagree
ㄴ Strongly disagree

17a. Please explain:

\section{CONTINUE 1}

[Note: All are directed to questions 19 and 20.] 1

\section{No Section 1}

18. If you do not have an advanced-subject degree, would you like to obtain one?

口 Yes a No

18a. If yes, why do you feel it would be beneficial? (Check all that apply.)

Job requirement

․ Help in job performance

- Help in career advancement

․ Higher salary

- Greater marketability when searching for a job

a Personal fulfillment

- Other, please describe:

18b. If no, why not? (Check all that apply.)

I I do not have the time.

I I do not have the money.

- My library does not support it.

I I do not want one.

I I do not think I need one.

- Appropriate graduate degree program is not accessible to me (i.e., none offered in my geographic area or through a distance education program).

- Other, please describe:

\section{CONTINUE 1}

[Note: All are directed to questions 19 and 20.] 1

19. Please provide any other general comments, including relevant personal experiences:

20. We may do a follow-up interview with selected participants. If you would be available to speak with us further about this subject, please provide your name, phone number, and e-mail address:

Name:

Phone number:

e-mail address:

Thank you for participating in this survey! 